\title{
Surface tension and spreading coefficient of single-and mix-pesticide solutions with aerial spraying organosilicone adjuvant
}

\author{
Yanhua Meng ${ }^{1,2}$, Meimei Wang ${ }^{1,2}$, Zhiguo Wang ${ }^{2,4}$, Hongyan $\mathrm{Hu}^{3 *}$, Yan $\mathrm{Ma}^{3 *}$ \\ (1. Anyang Institute of Technology, Anyang, 455000, China; \\ 2. Key Laboratory of Aviation Plant Protection, Ministry of Agriculture and Rural Affairs, Anyang, 455000, China; \\ 3. Institute of Cotton Research of the Chinese Academy of Agricultural Sciences, Anyang, 455000, China; \\ 4. Anyang Quanfeng Aviation Plant Protection Technology Co., Ltd, Anyang, 455000, China)
}

\begin{abstract}
Recently, unmanned aerial vehicles (UAVs) have been widely used to spray pesticides to control diseases and pests of many crops. During the process of pesticide application by UAV spraying, aerial spraying tank-mix adjuvants are usually mixed with pesticide solution to improve the efficiency of pesticides. Preventing pesticides depositing in off-target area is important in enhancing pesticide utilization. Improving the wetting and spreading of pesticides is one of the most important ways to reduce pesticide droplets running off from the target. This study is focusing on the effects of aerial spraying tank-mix organosilicone adjuvant (OA) on surface tension and spreading coefficient of pesticide solutions. Six pesticide solutions used alone and mixed together of different concentrations are prepared under field application conditions. Surface tension and spreading coefficient of the solution with and without OA were measured, respectively. The results show that OA could significantly lower surface tension and increase spreading coefficient of pesticide solutions regardless of solution concentrations. OA with concentration higher than critical micelle concentration (CMC) could not further decrease surface tension, but still could significantly increase spreading coefficient of the solution. For solutions with single pesticide belongs to different formulations, the minimum needed concentration of $\mathrm{OA}$ is different due to formulation type. The minimum concentration of $\mathrm{OA}$ for solution of suspension concentrate and aqueous solution $(0.5 \% 0-0.7 \%)$ is lower than that of solutions of emulsifiable concentrate (EC) $(2.0 \%-5.0 \%$ ). For solutions of several pesticides mixed together, the minimum concentration of OA is related to the number of EC formulation in the solution. For pesticide solutions containing one EC formulation, the minimum concentration of $\mathrm{OA}$ is $2.0 \%$; for pesticide solutions containing two or three EC formulation, the minimum concentration of OA is recommended to be $5.0 \%{ }^{-10.0 \%}$. These results suggest that the concentration of OA needed for pesticide solution should be evaluated before field application considering pesticide belonging to different formulations mixing together for application.

Keywords: aerial spraying adjuvant, organosilicone, surface tension, spreading coefficient
\end{abstract}

DOI: $10.33440 /$ j.ijpaa.20210401.159

Citation: Meng Y H, Wang M M, Wang Z G, Hu H Y, Ma Y. Surface tension and spreading coefficient of single-and mix-pesticide solutions with aerial spraying organosilicone adjuvant. Int J Precis Agric Aviat, 2021; 4(1): 6-13.

\section{Introduction}

Pesticide applications are one of crucial way to ensure the production and quality of agricultural products ${ }^{[1]}$. Improving the wettability of spraying liquid on the target crop surface is one of the effective ways to enhance the utilization efficiency of pesticide $^{[2]}$. During the application process, off-target deposits of pesticides and pesticides removed from agricultural crops due to rainfall might pollute the environment ${ }^{[3]}$. The efficiency of pesticides applied by spraying on leaves is depended on the amount of pesticide solution retains on leaf surface ${ }^{[4]}$. Most of plants have natural wax acting as a substantial barrier for wetting and spreading

Received date: 2021-02-20 Accepted: $2021-03-28$

Biographies: Yanhua Meng, $\mathrm{PhD}$, research interests: precision agricultural aviation application and pests \& diseases management, Email: yanhua.meng@ outlook.com; Meimei Wang, PhD, Associate Professor, research interests: agricultural aviation application, Email: 20160297@ayit.edu.cn; Zhiguo Wang, Senior Engineer, research interests: application technology of UAV for diseases and pests controlling, Email: 121489137@qq.com.

* Corresponding author: Yan Ma, Professor, research interests: agrochemicals research and application. Mailing Address: Key Laboratory of Aviation Plant Protection, Ministry of Agriculture and Rural Affairs, Anyang. Email: aymayan@126.com. Hongyan Hu, PhD, Associate Professor, research interests: agricultural aviation application and plant protection. Mailing Address: Key Laboratory of Aviation Plant Protection, Ministry of Agriculture and Rural Affairs, Anyang. Email: huhongyan1986@163.com. of pesticide droplets ${ }^{[5]}$. Water is a dilution solution for many pesticides. The surface tension of water is relatively high (surface tension of fresh water in different places might be different due to temperature difference and other conditions). When water is sprayed on the surface of hydrophobic plants, its retention capacity is very low because of surface tension of water is higher than that of the critical surface tension (CST) of plant surface ${ }^{[6]}$. In most cases of pesticide application by spraying, it is difficult for water to wet the leaves evenly. Therefore, it is necessary to add some tank-mix adjuvant into pesticide solution for better application ${ }^{[7]}$. The adjuvants can affect the physical and chemical parameters, such as volume median diameter and uniformity coefficient of droplets $^{[8]}$. Tank-mix adjuvant is used to aid or modify the action of an agrichemical, or the physicochemical properties of the mixture ${ }^{[9]}$. The adjuvant reduces the surface tension by accumulate its molecules at the air-water interface. The reduction of surface tension continues with the increasing of adjuvant concentration until the interface is saturated with adjuvant molecules. The concentration of tank-mix adjuvant at this point is called $\mathrm{CMC}^{[7]}$. Adjuvant that can rapidly reduce dynamic surface tension of the solution make surface tension of pesticide droplets less than CST of plant stems and leaves, so that the droplets can wet and spread easily on the plant surface, improving the efficiency of pesticides. In pesticide application process, agricultural tank-mix adjuvants are often used to enhance the control efficacy 
of disease, pest and weed ${ }^{[4]}$.

Agricultural silicone surfactants mainly include agricultural formula assistants and spray auxiliaries. The latter are widely used during pesticide application process. Organosilicone adjuvants (OAs) have an extreme spreading ability to wet the target surface by reducing surface tension and contact angle of aqueous solution (AS) ${ }^{[10,11]}$. Density of OAs is very similar to that of water, so they are relatively non-viscous and are readily poured, measured and dispersed in water ${ }^{[10]}$. In general, OAs can effectively promote the rapid absorption of pesticide solution and improve the utilization rate of pesticides by reducing the surface tension of water and increasing the expansion area of the solution on the target ${ }^{[12]}$.

Recently, small unmanned aerial vehicles (UAVs) are widely used for pesticide spraying application on wheat and rice ${ }^{[13,14]}$. Due to the advantages of high efficiency, flexibility and excellent water saving performance ${ }^{[15,16]}$, the development of UAVs in pest and disease control is rapid ${ }^{[17-19]}$. However, the downsides of UAVs are equally notable, such as high potential of drift risk ${ }^{[20,21]}$ because of the small droplet size and the long distance between nozzle and crop canopy compared to ground-based machine sprayers. Therefore, improving the disadvantages of UAV application is attracted the attention of researchers. UAV spraying pesticide by mixing appropriate adjuvant could improve pesticide utilization $^{[13]}$. When using UAV spraying water without adjuvant, $90 \%$ of drift droplets landed within a range of $10.1 \mathrm{~m}$ of the target area, while with $0.8 \%$ Silwet DRS-60 adjuvant (belonging to $\mathrm{OA}$ ) in water, the distance is shortened to $6.4 \mathrm{~m}^{[20]}$. Compared to distilled water, surface tension of distilled water mixing with tank-mix OA with concentration of $0.5 \%$ decreases by $64.7 \%$, and spreading coefficient increases by 74.5 times $^{[22]}$.

Due to low volume of UAV spraying, pesticides are diluted in water in high concentration. Furthermore, during the process of field application, several pesticides from the same formulation or different formulations are always mixed together in one application. Aerial spraying adjuvants are added into pesticide solution to improve the efficiency of pesticides. In this paper, followed UAV field application volume of 13.5-22.5 L/ha, six pesticides belonging to three formulations (emulsifiable concentrate (EC); suspension concentrate (SC) and AS ) are diluted with tap water alone or mixed together accordingly, and the effects of aerial spraying OA on surface tension reduction and spreading expansion of pesticide solutions are evaluated.

\section{Materials and methods}

\subsection{OA and pesticides}

The registered rate of aerial spraying tank-mix OA (QF-LY) used in this study is $1 \mathrm{~mL} / \mathrm{L}$, produced and provided by Anyang Quanfeng Biotechnology Co., Ltd. The basic information of insecticides, fungicides and plant growth regulator used are listed in Table 1. The pesticides are also produced and provided by the same company as the adjuvant.

Table 1 Pesticide formulations used in the study

\begin{tabular}{clcc}
\hline $\begin{array}{c}\text { Pesticide } \\
\text { classification }\end{array}$ & \multicolumn{1}{c}{$\begin{array}{c}\text { Common names } \\
\text { of pesticides }\end{array}$} & $\begin{array}{c}\text { Abbreviation } \\
\text { of common name }\end{array}$ & $\begin{array}{c}\text { Dosage } \\
/ \mathrm{mL} \cdot \mathrm{hm}^{-2}\end{array}$ \\
\hline \multirow{3}{*}{ Insecticide } & $\begin{array}{l}600 \mathrm{~g} / \mathrm{L} \text { imidacloprid SC } \\
4.5 \% \text { beta-cypermethrin EC }\end{array}$ & $\mathrm{I}$ & 90 \\
& $5 \%$ acetamiprid EC & $\mathrm{B}$ & 600 \\
\hline Fungicide & $30 \%$ tebuconazole SC & $\mathrm{T}$ & 600 \\
\hline $\begin{array}{c}\text { Plant growth } \\
\text { regulator }\end{array}$ & $\begin{array}{l}1.6 \% \text { diethyl aminoethyl } \\
\text { hexanoate AS }\end{array}$ & $\mathrm{M}$ & 450 \\
\hline
\end{tabular}

\subsection{Preparation of solutions}

In order to simulate the field application solution, tab water is used to prepare solutions. Solutions tested are prepared in series of spraying volumes $(13.5 \mathrm{~L} / \mathrm{ha}, 18.0 \mathrm{~L} / \mathrm{ha}$ and $22.5 \mathrm{~L} / \mathrm{ha})$ with high concentration, which are applied by UAV field application. Solutions are prepared in groups according to the application spraying volumes, pesticide formulations and concentration of OA. A series of solutions with different concentrations of $\mathrm{OA}$ and pesticide are prepared in very group solution.

\subsection{Surface tension and CMC of $\mathrm{OA}$}

Surface tensions of the tested solutions are measured by ZL-2 automatic tensiometer (made by Shandong Sanbengkesen Instrument Co., Ltd.) using ring method under non-equilibrium conditions. The measurement range of the tensiometer is 5$95 \mathrm{mN} / \mathrm{m}$ and the sensitivity threshold is $0.1 \mathrm{mN} / \mathrm{m}$.

The tensiometer is calibrated before measurements. Surface tension of every solution is measured three times to calculate an average value. Indoor laboratory for measuring surface tension is kept at constant temperature $21 \pm 0.2^{\circ} \mathrm{C}$.

When adjuvant concentration reaches CMC value, the surface tension does not decrease with the increasing of adjuvant concentration. The CMC value of adjuvant is usually measured by surface tension and electrical conductance methods. If the former method is applied, when the surface adsorption reaches saturation, the turning point of the curve is CMC value, which is suitable for both ionic and non-ionic surfactants. After reaching $\mathrm{CMC}$ value, surface tension value is kept unchanged and is not affected by adjuvant concentration. Therefore, CMC could also be determined by measuring the surface tension of surfactant aqueous solutions with different concentrations. When the surface tension remains basically unchanged, the lowest concentration is $\mathrm{CMC}$ value ${ }^{[23]}$. In this study, the $\mathrm{CMC}$ of the adjuvant aqueous solution is determined by surface tension method.

\subsection{Spreading coefficient}

Pesticide wetting test cards (WTCs) prepared by Institute of plant protection, Chinese Academy of Agricultural Sciences are used to measure spreading coefficient, wherein the spreading coefficient is defined as the spreading area of $20 \mu \mathrm{L}$ liquid on WTC. According to Zhang et $\mathrm{al}^{[24]}$, the wettability of different pesticide solutions can be measured by spreading coefficient. The contact angles of water on WTC and wheat leaves are $104.5^{\circ}$ and $109.3^{\circ}$, respectively. It can be considered that the wetting conditions of water on WTCs and wheat leaves are similar ${ }^{[24]}$. In the measurements, the spreading area of $20 \mu \mathrm{L}$ water on WTC is defined as a reference, while the spreading area of the pesticide solution on the WTC is measured and normalized to the reference. Pesticide solution of $20 \mu \mathrm{L}$ is transferred onto the center of WTC with a pipette gun or other liquid extractor. The solution will spread on the WTC, and the part of the WTC contacting with the solution liquid will change color. After the solution stops spreading, the number of cells occupied by color is counted. The number of colored cells is the spreading coefficient of the solution on the WTC. Spreading coefficient of each solution is measured for once.

In this study, the influence of various concentrations of OA on water surface tension and spreading coefficient is researched to determine the $\mathrm{CMC}$ value. Then, surface tension and spreading coefficient of different concentration of single- or mix-pesticide formulation solutions are measured.

\subsection{Statistical analyses}

Means are compared using Duncan's multiple range test at $\alpha=$ 
0.05 in software of SPSS 16.0 (IBM, Chicago, USA).

\section{Results}

\subsection{OA aqueous solution}

In order to study the effect of different concentration of OA on the surface tension and spreading coefficient of aqueous solution, gradient adjuvant concentrations are added to tap water to measure the change of surface tension and spreading coefficient. The results are shown in Table 2.

Table 2 Effects of spraying adjuvant concentration on surface tension and Spreading coefficient of water

\begin{tabular}{ccc}
\hline Adjuvant concentration/\%o & Surface tension $/ \mathrm{mN} \cdot \mathrm{m}^{-1}$ & Spreading coefficient \\
\hline 0 & $57.0 \pm 0.8 \mathrm{a}$ & 1 \\
0.1 & $22.2 \pm 0.2 \mathrm{~b}$ & 4 \\
0.2 & $21.6 \pm 0.3 \mathrm{~b}$ & 10 \\
0.5 & $20.8 \pm 0.4 \mathrm{c}$ & 34 \\
0.7 & $20.7 \pm 0.3 \mathrm{c}$ & 63 \\
0.8 & $20.5 \pm 0.3 \mathrm{c}$ & 64 \\
1.0 & $20.8 \pm 0.1 \mathrm{c}$ & 74 \\
1.1 & $20.9 \pm 0.2 \mathrm{c}$ & 84 \\
\hline
\end{tabular}

Note: a. Surface tension values are shown as "mean \pm SD"; b. Different lowercase letters mean significant difference at $\alpha=0.05$.

As shown in Table 2, the surface tension of tap water without $\mathrm{OA}$ is $57.0 \mathrm{mN} / \mathrm{m}$. After adding different concentrations of adjuvant, the surface tension decreases to $20.2-22.2 \mathrm{mN} / \mathrm{m}$, and then it keeps at a stable value when adjuvant concentration reaches $0.5 \%$. According to $\mathrm{Gu}$ et al ${ }^{[23]}$, the $\mathrm{CMC}$ value of $\mathrm{OA}$ can be determined as $0.5 \%$, and the corresponding surface tension is $20.8 \mathrm{mN} / \mathrm{m}$. After adding the above series of concentrations into water, the spreading coefficients of water increase from 4 to 84 with the increase of OA concentration. Thus, while pesticides diluted by water for application, considering the influence of wetting spreading effect on the control efficacy, especially for those pesticides with contact effect, the recommended concentration of $\mathrm{OA}$ is $0.7-1.0 \%$. For systemic pesticides, the recommended concentration of the adjuvant is $0.5 \%$.

\subsection{Single pesticide formulation solutions}

The physicochemical properties of pesticide solution are different from those of water. In this section, pesticides of SC, EC and AS are diluted into a series of concentrations with water respectively. Then the adjuvant with different concentrations is added into the solution. Concentrations of the solution are similar to field application by UAV. After the preparation, the surface tension and spreading coefficient of pesticide solutions are measured immediately.

Tebuconazole solution. As shown in Table 3, before the adjuvant is added, the surface tensions of tebuconazole solution of $3.0 \mathrm{~mL} / \mathrm{L}(37.3 \mathrm{mN} / \mathrm{m})$ and $6.0 \mathrm{~mL} / \mathrm{L}(38.3 \mathrm{mN} / \mathrm{m})$ are significantly lower than that of other concentrations. However, there is no significant difference among the surface tension of other concentrations, with an average of $40.4 \mathrm{mN} / \mathrm{m}$. The spreading coefficient is 1.5 when the concentration of tebuconazole solution is between 3.0-20.0 mL/L. While the concentration of tebuconazole solution is $23.3-33.3 \mathrm{~mL} / \mathrm{L}$, the spreading coefficient is 2. It can be considered that the spreading coefficient of tebuconazole solution with high concentration has no significant relationship with the concentration of tebuconazole solution without mixing adjuvant.

Surface tension and spreading coefficient of tebuconazole solution have been changed after the adjuvant is mixed with the solution. When the adjuvant concentration is less than $\mathrm{CMC}$, the spreading coefficient is $5-8$ and surface tension is $22.9-23.9 \mathrm{mN} / \mathrm{m}$. At $\mathrm{CMC}$, the surface tension is $22.7 \mathrm{mN} / \mathrm{m}$, which is slightly higher than that of water $(20.8 \mathrm{mN} / \mathrm{m})$ with adjuvant of the same concentration. And the spreading coefficient of the solution is one half of that of water with adjuvant concentration of CMC. While Adjuvant concentration keeps unchangeable and tebuconazole concentrations is changed, it could be found that, the higher concentration of tebuconazole solution is, the smaller the spreading coefficient is. Compared to water, the spreading coefficient of tebuconazole solution with different concentrations of OA changes less than that of water. However, the adjuvant has obvious ability to promote the spreading of tebuconazole solution. Therefore, for the aerial application with low volume and high concentration, the adjuvant might improve the wetting and spreading of tebuconazole solution on the target surface obviously. However, when the concentration of the adjuvant is CMC, increasing the adjuvant concentration cannot improve wetting and spreading of the solutions, which is different from water with adjuvant concentration above CMC. This may be due to the physical and chemical properties of tebuconazole solution.

Table 3 The surface tension and spreading coefficient of tebuconazole solution under different concentrations with or without OA

\begin{tabular}{|c|c|c|c|}
\hline $\begin{array}{l}\text { Tebuconazole solution } \\
\text { concentration } / \mathrm{mL} \cdot \mathrm{L}^{-1}\end{array}$ & $\begin{array}{c}\text { Adjuvant } \\
\text { concentration/\%o }\end{array}$ & $\begin{array}{l}\text { Surface tension } \\
\qquad / \mathrm{mN} \cdot \mathrm{m}^{-1}\end{array}$ & $\begin{array}{l}\text { Spreading } \\
\text { coefficient }\end{array}$ \\
\hline 33.3 & 0 & $40.6 \pm 0.2 \mathrm{a}$ & 2 \\
\hline 30 & 0 & $40.5 \pm 0.2 \mathrm{a}$ & 2 \\
\hline 25 & 0 & $40.4 \pm 0.3 \mathrm{a}$ & 2 \\
\hline 23.3 & 0 & $40.5 \pm 0.3 \mathrm{a}$ & 2 \\
\hline 20 & 0 & $40.4 \pm 0.1 \mathrm{a}$ & 1.5 \\
\hline 17.5 & 0 & $40.3 \pm 0.2 \mathrm{a}$ & 1.5 \\
\hline 16 & 0 & $40.2 \pm 0.2 \mathrm{a}$ & 1.5 \\
\hline 15 & 0 & $40.4 \pm 0.2 \mathrm{a}$ & 1.5 \\
\hline 14 & 0 & $40.1 \pm 0.3 \mathrm{a}$ & 1.5 \\
\hline 6 & 0 & $38.3 \pm 0.3 b$ & 1.5 \\
\hline 3 & 0 & $37.3 \pm 0.3 b$ & 1.5 \\
\hline 33.3 & 1.1 & $22.6 \pm 0.2 a$ & 26 \\
\hline 26.7 & 1.1 & $22.1 \pm 0.5 \mathrm{a}$ & 31 \\
\hline 23.3 & 1.1 & $22.0 \pm 0.2 \mathrm{a}$ & 33 \\
\hline 30 & 1 & $22.7 \pm 0.4 a$ & 29 \\
\hline 17.5 & 0.8 & $22.6 \pm 0.3 a$ & 30 \\
\hline 20 & 0.8 & $22.7 \pm 0.3 \mathrm{a}$ & 29 \\
\hline 25 & 0.8 & $22.5 \pm 0.2 \mathrm{a}$ & 24 \\
\hline 20 & 0.7 & $22.7 \pm 0.5 \mathrm{a}$ & 22 \\
\hline 16 & 0.7 & $22.4 \pm 0.2 \mathrm{a}$ & 27 \\
\hline 14 & 0.7 & $22.4 \pm 0.3 \mathrm{a}$ & 28 \\
\hline 15 & 0.5 & $22.7 \pm 0.4 \mathrm{a}$ & 17.7 \\
\hline 6 & 0.2 & $22.9 \pm 0.2 \mathrm{a}$ & 8 \\
\hline 3 & 0.1 & $23.9 \pm 0.2 \mathrm{a}$ & 5 \\
\hline
\end{tabular}

Notes: a. Surface tension values are denoted as "mean \pm SD"; $b$. The significance analysis of surface tension is divided into two groups: the group without adjuvant and the group with adjuvant; c. The same lowercase letters mean no significant difference in the same group at $\alpha=0.05$.

Imidacloprid solution. It can be seen from Table 4 that the concentration of imidacloprid solution has little effect on the spreading coefficient, but has a significant effect on surface tension. The surface tension of imidacloprid solution with concentration of $2.8 \mathrm{~g} / \mathrm{L}$ is $46.2 \mathrm{mN} / \mathrm{m}$, which is significantly higher than that of 
other concentrations. Surface tension (43.4 $\mathrm{mN} / \mathrm{m})$ of imidacloprid solution with concentration of $5.0 \mathrm{~g} / \mathrm{L}$ is significantly higher than that $(40.7-41.5 \mathrm{mN} / \mathrm{m})$ of imidacloprid solution with concentration of $3.2-4.0 \mathrm{~g} / \mathrm{L}$.

Table 4 Surface tension and spreading coefficient of imidacloprid with different concentrations with or without aerial spraying $O A$

\begin{tabular}{cccc}
\hline $\begin{array}{c}\text { Imidacloprid solution } \\
\text { Concentration } / \mathrm{g} \cdot \mathrm{L}^{-1}\end{array}$ & $\begin{array}{c}\text { Adjuvant } \\
\text { concentration/\%o }\end{array}$ & $\begin{array}{c}\text { Surface tension } \\
/ \mathrm{mN} \cdot \mathrm{m}^{-1}\end{array}$ & $\begin{array}{c}\text { Spreading } \\
\text { coefficient }\end{array}$ \\
\hline 2.8 & 0 & $46.2 \pm 0.3 \mathrm{a}$ & 2 \\
3.2 & 0 & $40.7 \pm 0.3 \mathrm{c}$ & 1 \\
3.5 & 0 & $40.7 \pm 0.1 \mathrm{c}$ & 1 \\
4.0 & 0 & $41.5 \pm 0.2 \mathrm{c}$ & 1 \\
5.0 & 0 & $43.4 \pm 0.3 \mathrm{~b}$ & 1 \\
2.8 & 0.7 & $21.1 \pm 0.5 \mathrm{a}$ & 63 \\
3.2 & 0.7 & $21.3 \pm 1.0 \mathrm{a}$ & 58 \\
4.0 & 0.7 & $18.8 \pm 0.5 \mathrm{~b}$ & 48 \\
3.5 & 0.8 & $18.0 \pm 0.1 \mathrm{~b}$ & 42 \\
4.0 & 0.8 & $20.5 \pm 0.3 \mathrm{a}$ & 60 \\
5.0 & 0.8 & $20.5 \pm 0.2 \mathrm{a}$ & 70 \\
4.7 & 1.1 & $20.9 \pm 0.3 \mathrm{a}$ & 84 \\
5.3 & 1.1 & $20.9 \pm 0.3 \mathrm{a}$ & 96 \\
6.7 & 1.1 & $21.0 \pm 0.1 \mathrm{a}$ & 110 \\
\hline
\end{tabular}

Notes: a. Surface tension values are indicated as "mean \pm SD"; b. The significance analysis of surface tension is divided into two groups: the group without adjuvant and the group with adjuvant; c. Different lowercase letters mean significant difference in the same group at $\alpha=0.05$.

After adding $\mathrm{OA}$ with different concentrations to the solution, surface tension decreases notably from $40.7-46.2 \mathrm{mN} / \mathrm{m}$ to 18.0 $21.3 \mathrm{mN} / \mathrm{m}$, and the spreading coefficient increases significantly from 1-2 to 42-110. With the OA concentration of $0.7 \%$, the spreading coefficient decreases with the increase of imidacloprid concentration. With the OA concentration of $0.8 \%$ and $1.1 \%$, the spreading coefficient increases with the increase of imidacloprid concentration. This may be caused by the interaction between imidacloprid concentration and the adjuvant concentration and physicochemical properties of the solution. Thus, in field operation, the surface tension of imidacloprid solution mixed with the adjuvant of three concentrations is significantly less than the CST of wheat $(36.26-39.00 \mathrm{mN} / \mathrm{m})^{[25]}$, and the spreading coefficient is more than 40.

Diethyl aminoethyl hexanoate (AS) solution. As shown in Table 5, before the addition of adjuvant, the surface tension of diethyl aminoethyl hexanoater solution with different concentrations is $53.9-55.6 \mathrm{mN} / \mathrm{m}$, which is slightly lower than that of tap water $(57 \mathrm{mN} / \mathrm{m})$; the spreading coefficient of the solution is 1 , which is the same as that of clean water. Therefore, the surface tension and spreading coefficient are not affected by the concentration of diethyl aminoethyl hexanoater before the addition of the adjuvant. After the solutions mixed with the adjuvant with different concentrations, the surface tension of diethyl aminoethyl hexanoater decreases to $20.2-21.2 \mathrm{mN} / \mathrm{m}$, which is consistent with the surface tension of the adjuvant with concentration greater than or equal to CMC in Table 2. The spreading coefficient of diethyl aminoethyl hexanoater solution increases with the increase of the concentration of the adjuvant. The spreading coefficients of the three adjuvant concentrations $0.7 \%, 0.8 \%$ and $1.1 \%$ are 61,82 and 90 , respectively.

Beta-cypermethrin (EC) solution. It can be seen from Table 6 that the surface tension of beta-cypermethrin solution without the adjuvant is not affected by the concentrations, except that $\left(30.0 \mathrm{mN} \cdot \mathrm{m}^{-1}\right)$ for the solution with concentration of $31.1 \mathrm{~mL} / \mathrm{L}$. Before the addition of additives, the spreading coefficient of beta-cypermethrin solution is 2-3.5 when the solution concentration is less than or equal to $26.7 \mathrm{~mL} / \mathrm{L}$, and 4 when the solution concentration is $31.1-44.4 \mathrm{~mL} / \mathrm{L}$. The results show that the surface tension decreases to $22.0-24.8 \mathrm{mN} / \mathrm{m}$ with the addition of adjuvant with different concentrations, and there is no significant difference in the surface tension of other concentrations except the solution concentration of $31.1 \mathrm{~mL} / \mathrm{L}$. When the adjuvant concentration is $0.7-1.1 \%$, the spreading coefficient is $6-9$. The spreading coefficient increases significantly from 6-9 to $67-78$ when the adjuvant with the concentration of $2.0-10.0 \%$ is added in into the solutions, respectively. Beta-cypermethrin EC is a kind of non-inhibitive insecticide, which has the effects of contact and stomach toxicity. Therefore, in the process of the pesticide with low volume and high concentration application by UAV to control pests in wheat field, it is suggested that the minimum concentration of OA should be $2.00 \%$ in order to make the solution better spread on the target.

Myclobutanil solution (EC). As shown in Table 7, before the addition of additives, the surface tension and spreading coefficient of myclobutanil solution without the adjuvant are not affected by its concentration, the surface tension is $34.6 \mathrm{mN} / \mathrm{m}$, and the spreading coefficient is 2-3. After adding the adjuvant with different concentrations, the surface tension of the solution decreases to $26 \mathrm{mN} / \mathrm{m}$. When the concentration of the adjuvant is $0.7-2.0 \%$, the spreading coefficient of myclobutanil solution is 4.5-6, slightly higher than that of the solutions without adjuvant. With the adjuvant concentrations of $5.0 \%$ and $10.0 \%$, the spreading coefficients were 16 and 45, respectively. Myclobutanil is a kind of internal absorption fungicide which has both protective and therapeutic effects. Therefore, in the low volume and high concentration spraying process by UAV, it is suggested that the adjuvant concentration is $5.0 \%$ while the pesticide diluted with water is applied alone in order to facilitate the agent wetting and spreading on the target.

Table 5 Surface tension and spreading coefficient of diethyl aminoethyl hexanoate (DA-6) AS with different concentrations with or without aerial spraying $\mathrm{OA}$

\begin{tabular}{cccc}
\hline $\begin{array}{c}\text { Diethyl aminoethyl hexanoate } \\
\text { solutionconcentration } / \mathrm{mL} \cdot \mathrm{L}^{-1}\end{array}$ & $\begin{array}{c}\text { Adjuvant } \\
\text { concentration } / \% 0\end{array}$ & $\begin{array}{c}\text { Surface tension } \\
/ \mathrm{mN} \cdot \mathrm{m}^{-1}\end{array}$ & $\begin{array}{c}\text { Spreading } \\
\text { coefficient }\end{array}$ \\
\hline 9.3 & 0 & $54.6 \pm 0.6 \mathrm{a}$ & 1 \\
10.7 & 0 & $53.9 \pm 0.8 \mathrm{a}$ & 1 \\
11.7 & 0 & $54.5 \pm 0.6 \mathrm{a}$ & 1 \\
13.3 & 0 & $54.8 \pm 0.4 \mathrm{a}$ & 1 \\
15.6 & 0 & $54.6 \pm 0.7 \mathrm{a}$ & 1 \\
16.7 & 0 & $55.2 \pm 0.7 \mathrm{a}$ & 1 \\
17.8 & 0 & $54.7 \pm 0.6 \mathrm{a}$ & 1 \\
22.2 & 0 & $55.6 \pm 0.7 \mathrm{a}$ & 1 \\
9.3 & 0.7 & $20.9 \pm 0.7 \mathrm{a}$ & 59 \\
10.7 & 0.7 & $20.8 \pm 0.9 \mathrm{a}$ & 62 \\
16.7 & 0.7 & $21.1 \pm 0.8 \mathrm{a}$ & 62 \\
11.7 & 0.8 & $20.8 \pm 0.5 \mathrm{a}$ & 83 \\
13.3 & 0.8 & $21.2 \pm 0.8 \mathrm{a}$ & 82 \\
16.7 & 0.8 & $20.9 \pm 0.6 \mathrm{a}$ & 82 \\
15.6 & 1.1 & $20.8 \pm 0.6 \mathrm{a}$ & 89 \\
17.8 & 1.1 & $20.4 \pm 0.7 \mathrm{a}$ & 90 \\
22.2 & 1.1 & $20.2 \pm 0.5 \mathrm{a}$ & 91 \\
\hline
\end{tabular}

Notes: a. Surface tension values are indicated as "mean \pm SD"; b. The significance analysis of surface tension is divided into two groups: the group without adjuvant and the group with adjuvant; c. Different lowercase letters mean significant difference in the same group at $\alpha=0.05$. 
Table 6 Surface tension and spreading coefficient of beta-cypermethrin with different concentrations with or without aerial spraying $O A$

\begin{tabular}{cccc}
\hline $\begin{array}{c}\text { Beta-cypermethrin solution } \\
\text { concentration } / \mathrm{mL}^{-1}\end{array}$ & $\begin{array}{c}\text { Adjuvant } \\
\text { concentration/\%o }\end{array}$ & $\begin{array}{c}\text { Surface tension } \\
/ \mathrm{mN} \cdot \mathrm{m}^{-1}\end{array}$ & $\begin{array}{c}\text { Spreading } \\
\text { coefficient }\end{array}$ \\
\hline 18.7 & 0 & $30.3 \pm 0.5 \mathrm{a}$ & 2 \\
21.3 & 0 & $30.9 \pm 0.2 \mathrm{a}$ & 3 \\
23.7 & 0 & $30.1 \pm 0.1 \mathrm{a}$ & 3.5 \\
26.7 & 0 & $30.7 \pm 0.6 \mathrm{a}$ & 3.5 \\
31.1 & 0 & $28.6 \pm 0.1 \mathrm{~b}$ & 4 \\
33.3 & 0 & $29.1 \pm 0.1 \mathrm{a}$ & 4 \\
35.6 & 0 & $30.2 \pm 0.1 \mathrm{a}$ & 4 \\
44.4 & 0 & $29.1 \pm 0.1 \mathrm{a}$ & 4 \\
18.7 & 0.7 & $24.3 \pm 0.3 \mathrm{a}$ & 6 \\
21.3 & 0.7 & $25.2 \pm 0.2 \mathrm{a}$ & 6 \\
26.7 & 0.7 & $24.4 \pm 0.3 \mathrm{a}$ & 6 \\
23.3 & 0.8 & $23.6 \pm 0.2 \mathrm{a}$ & 7 \\
26.7 & 0.8 & $23.2 \pm 0.1 \mathrm{a}$ & 8 \\
33.3 & 0.8 & $23.5 \pm 0.3 \mathrm{a}$ & 9 \\
31.1 & 1.1 & $22.0 \pm 0.2 \mathrm{~b}$ & 9 \\
35.6 & 1.1 & $24.0 \pm 0.1 \mathrm{a}$ & 9 \\
44.4 & 1.1 & $24.8 \pm 0.3 \mathrm{a}$ & 9 \\
40.0 & 1.0 & $24.5 \pm 0.3 \mathrm{a}$ & 9 \\
40.0 & 2.0 & $24.1 \pm 0.1 \mathrm{a}$ & 67 \\
40.0 & 5.0 & $24.3 \pm 0.2 \mathrm{a}$ & 68 \\
40.0 & 10.0 & $24.4 \pm 0.3 \mathrm{a}$ & 78 \\
\hline
\end{tabular}

Notes: a. Surface tension values are denoted as "mean \pm SD"; $b$. The significance analysis of surface tension is divided into two groups: the group without adjuvant and the group with adjuvant; $\mathrm{c}$. The same lowercase letters mean no significant difference in the same group at $\alpha=0.05$.

Table 7 Surface tension and spreading coefficient of myclobutanil EC solution with different concentrations with or without aerial spraying $\mathrm{OA}$

\begin{tabular}{|c|c|c|c|}
\hline $\begin{array}{l}\text { Myclobutanil solution } \\
\text { concentration } / \mathrm{mL} \cdot \mathrm{L}^{-1}\end{array}$ & $\begin{array}{c}\text { Adjuvant } \\
\text { concentration/\%o }\end{array}$ & $\begin{array}{l}\text { Surface tension } \\
\qquad / \mathrm{mN} \cdot \mathrm{m}^{-1}\end{array}$ & $\begin{array}{l}\text { Spreading } \\
\text { coefficient }\end{array}$ \\
\hline 14.0 & 0 & $34.2 \pm 0.3 \mathrm{a}$ & 2.5 \\
\hline 16.0 & 0 & $34.8 \pm 0.4 \mathrm{a}$ & 2.5 \\
\hline 17.5 & 0 & $34.4 \pm 0.2 \mathrm{a}$ & 3 \\
\hline 20.0 & 0 & $34.5 \pm 0.7 \mathrm{a}$ & 2.5 \\
\hline 23.3 & 0 & $34.7 \pm 0.2 \mathrm{a}$ & 2.5 \\
\hline 25.0 & 0 & $34.8 \pm 0.4 \mathrm{a}$ & 2.5 \\
\hline 26.7 & 0 & $34.6 \pm 0.3 \mathrm{a}$ & 2 \\
\hline 33.3 & 0 & $34.6 \pm 0.4 a$ & 2.5 \\
\hline 14.0 & 0.7 & $25.6 \pm 0.4 a$ & 5 \\
\hline 16.0 & 0.7 & $25.7 \pm 0.6 \mathrm{a}$ & 5 \\
\hline 20.0 & 0.7 & $25.5 \pm 0.3 \mathrm{a}$ & 5 \\
\hline 17.5 & 0.8 & $25.6 \pm 0.3 \mathrm{a}$ & 6 \\
\hline 20.0 & 0.8 & $26.6 \pm 0.6 \mathrm{a}$ & 5.5 \\
\hline 25.0 & 0.8 & $26.9 \pm 0.3 \mathrm{a}$ & 5 \\
\hline 23.3 & 1.1 & $26.9 \pm 0.7 \mathrm{a}$ & 5 \\
\hline 26.7 & 1.1 & $25.5 \pm 0.6 \mathrm{a}$ & 4.5 \\
\hline 33.3 & 1.1 & $25.7 \pm 0.6 \mathrm{a}$ & 5 \\
\hline 30.0 & 1.0 & $26.8 \pm 0.3 \mathrm{a}$ & 4.5 \\
\hline 30.0 & 2.0 & $25.9 \pm 0.4 a$ & 6 \\
\hline 30.0 & 5.0 & $25.5 \pm 0.5 \mathrm{a}$ & 16 \\
\hline 30.0 & 10.0 & $25.7 \pm 0.7 \mathrm{a}$ & 45 \\
\hline
\end{tabular}

Notes: a. Surface tension values are denoted as "mean \pm SD"; $b$. The significance analysis of surface tension is divided into two groups: the group without adjuvant and the group with adjuvant; c. The same lowercase letters mean no significant difference in the same group at $\alpha=0.05$.

Acetamiprid solution (EC). As shown in Table 8, the surface tension $(33.0 \mathrm{mN} / \mathrm{m})$ and spreading coefficient (3.5-4) of acetamiprid EC solution without the adjuvant are independent of the concentration of the solution. The surface tension decreases from $33 \mathrm{mN} / \mathrm{m}$ to $26.0 \mathrm{mN} / \mathrm{m}$, and the spreading coefficient increases slightly from 3.5-4 to 6-8 at the adjuvant concentration of $0.7-1.1 \%$. When the concentration of the adjuvant is increased to $2.0 \%$, the spreading coefficient is 11 . While the concentrations of the adjuvant are $5.0 \%$ and $10.0 \%$, the spreading coefficients are 44 and 80 , respectively. Acetamiprid EC is a kind of insecticide taking effect with contact, stomach and internal absorption. Therefore, if the acetamiprid diluted with water is used alone in the low volume and high concentration aerial spray, it is recommended that the minimum concentration of the adjuvant is $5.0 \%$ when the insect population is in severe occurrence. The minimum concentration of the adjuvant used with the pesticide is $2.0 \%$ for aerial application by UAV.

Table 8 Surface tension and spreading coefficient of acetamiprid EC solution with different concentrations with or without aerial spraying $\mathrm{OA}$

\begin{tabular}{|c|c|c|c|}
\hline $\begin{array}{l}\text { Acetamiprid solution } \\
\text { concentration } / \mathrm{mL} \cdot \mathrm{L}^{-1}\end{array}$ & $\begin{array}{c}\text { Adjuvant } \\
\text { concentration/\%o }\end{array}$ & $\begin{array}{l}\text { Surface tension } \\
\qquad / \mathrm{mN} \cdot \mathrm{m}^{-1}\end{array}$ & $\begin{array}{l}\text { Spreading } \\
\text { coefficient }\end{array}$ \\
\hline 18.7 & 0 & $32.8 \pm 0.1 \mathrm{a}$ & 4 \\
\hline 21.3 & 0 & $33.1 \pm 0.2 \mathrm{a}$ & 3.8 \\
\hline 23.3 & 0 & $32.8 \pm 0.2 \mathrm{a}$ & 4 \\
\hline 26.7 & 0 & $33.2 \pm 0.1 \mathrm{a}$ & 3.8 \\
\hline 31.1 & 0 & $33.3 \pm 0.1 \mathrm{a}$ & 3.5 \\
\hline 33.3 & 0 & $33.3 \pm 0.2 \mathrm{a}$ & 3.8 \\
\hline 35.6 & 0 & $33.1 \pm 0.1 \mathrm{a}$ & 3.8 \\
\hline 44.4 & 0 & $32.8 \pm 0.2 \mathrm{a}$ & 3.5 \\
\hline 18.7 & 0.7 & $25.5 \pm 0.2 \mathrm{a}$ & 8 \\
\hline 21.3 & 0.7 & $25.7 \pm 0.3 \mathrm{a}$ & 7 \\
\hline 26.7 & 0.7 & $25.4 \pm 0.2 \mathrm{a}$ & 6.5 \\
\hline 23.3 & 0.8 & $25.9 \pm 0.3 \mathrm{a}$ & 7.5 \\
\hline 26.7 & 0.8 & $26.1 \pm 0.2 \mathrm{a}$ & 6 \\
\hline 33.3 & 0.8 & $26.1 \pm 0.1 \mathrm{a}$ & 6.8 \\
\hline 31.1 & 1.1 & $25.8 \pm 0.3 \mathrm{a}$ & 7 \\
\hline 35.6 & 1.1 & $25.7 \pm 0.3 \mathrm{a}$ & 7.5 \\
\hline 44.4 & 1.1 & $26.2 \pm 0.4 a$ & 6 \\
\hline 40.0 & 1.0 & $26.1 \pm 0.2 \mathrm{a}$ & 6 \\
\hline 40.0 & 2.0 & $26.3 \pm 0.2 \mathrm{a}$ & 11 \\
\hline 40.0 & 5.0 & $25.8 \pm 0.1 \mathrm{a}$ & 44 \\
\hline 40.0 & 10.0 & $25.5 \pm 0.2 \mathrm{a}$ & 80 \\
\hline
\end{tabular}

Notes: a. Surface tension values are denoted as "mean \pm SD"; b. The significance analysis of surface tension is divided into two groups: the group without adjuvant and the group with adjuvant; c. The same lowercase letters mean no significant difference in the same group at $\alpha=0.05$.

\subsection{Pesticide mixed formulation solutions}

In order to clarify the effect of the OA on the surface tension and spreading coefficient of pesticide mixed solutions, the surface tension and spreading coefficient of pesticide mixed solutions with different concentrations before and after the addition of the adjuvant are measured. In this section, the spreading coefficient and surface tension of three pesticide mixed formulations with and without the adjuvant are tested. Four pesticides listed in Table 1 are mixed in three groups as shown in the following. Pesticides in Group 1 are imidacloprid SC, beta-cypermethrin EC, tebuconazole SC and diethyl aminoethyl hexanoate AS; Group 2 are imidacloprid SC, beta-cypermethrin EC, myclobutanil EC and diethyl aminoethyl hexanoate AS; Group 3 are acetamiprid EC, beta-cypermethrin EC, myclobutanil EC and diethyl aminoethyl hexanoate AS.

Group 1 (SC+EC+SC+AS). As shown in Table 9, before the mixture of the adjuvant, the surface tension of Group 1 solutions with different concentrations is $30.8-32.2 \mathrm{mN} / \mathrm{m}$, and the spreading coefficient is 3.8-4. After addition of the adjuvant with three 
concentrations $(0.7,0.8$ and $1.1 \%)$, the surface tensions of Group 1 solutions are $25.3-26.5 \mathrm{mN} / \mathrm{m}$, and the spreading coefficient increases slightly from 3.8-4 to 5-7. In this group, the spreading coefficient does not increase significantly after the solutions mixed with the adjuvant, which may be due to the physicochemical properties of the group of solutions. The physicochemical properties of beta cypermethrin EC in this group may contribute to this. It can be seen from the above changes of spreading coefficient of beta cypermethrin EC before and after mixing with the adjuvant that the spreading coefficient of beta cypermethrin EC solution increases significantly when the concentration of adjuvant is $2.0 \%$ (Table 6). Therefore, it is speculated that the concentration of the adjuvant should be at least $2.0 \%$ when Group 1 solution is applied in field application by UAV.

Table 9 Surface tension and spreading coefficient of Group 1 solutions with different concentrations with or without aerial spraying OA

\begin{tabular}{cccc}
\hline $\begin{array}{c}\text { Concentrations of } \\
\text { Group 1 solution } / \mathrm{ml} \cdot \mathrm{L}^{-1} \\
(\mathrm{I}+\mathrm{B}+\mathrm{T}+\mathrm{D})\end{array}$ & $\begin{array}{c}\text { Adjuvant } \\
\text { concentration/\% }\end{array}$ & $\begin{array}{c}\text { Surface tension } \\
/ \mathrm{mN} \cdot \mathrm{m}^{-1}\end{array}$ & $\begin{array}{c}\text { Spreading } \\
\text { coefficient }\end{array}$ \\
\hline $2.8+18.7+14.0+9.3$ & 0 & $31.1 \pm 0.4 \mathrm{a}$ & 4 \\
$2.8+18.7+14.0+9.3$ & 0.7 & $25.6 \pm 0.2 \mathrm{~b}$ & 7 \\
$3.2+21.3+16.0+10.6$ & 0 & $32.1 \pm 0.5 \mathrm{a}$ & 4 \\
$3.2+21.3+16.0+10.6$ & 0.7 & $25.4 \pm 0.2 \mathrm{~b}$ & 5.5 \\
$4.0+26.7+20.0+13.3$ & 0 & $32.1 \pm 0.4 \mathrm{a}$ & 3.8 \\
$4.0+26.7+20.0+13.3$ & 0.7 & $25.7 \pm 0.3 \mathrm{~b}$ & 5 \\
$3.5+23.3+17.5+11.7$ & 0 & $31.8 \pm 0.6 \mathrm{a}$ & 4.3 \\
$3.5+23.3+17.5+11.7$ & 0.8 & $26.5 \pm 0.4 \mathrm{~b}$ & 6.5 \\
$4.0+26.7+20.0+13.3$ & 0 & $32.0 \pm 0.4 \mathrm{a}$ & 4.3 \\
$4.0+26.7+20.0+13.3$ & 0.8 & $25.3 \pm 0.3 \mathrm{~b}$ & 6.5 \\
$5.0+33.3+25.0+16.7$ & 0 & $32.1 \pm 0.4 \mathrm{a}$ & 4.0 \\
$5.0+33.3+25.0+16.7$ & 0.8 & $25.8 \pm 0.2 \mathrm{~b}$ & 5.5 \\
$4.7+31.1+23.3+15.6$ & 0 & $32.2 \pm 0.3 \mathrm{a}$ & 4 \\
$4.7+31.1+23.3+15.6$ & 1.1 & $25.7 \pm 0.6 \mathrm{c}$ & 7 \\
$5.3+35.6+26.7+17.8$ & 0 & $31.8 \pm 0.4 \mathrm{ab}$ & 4 \\
$5.3+35.6+26.7+17.8$ & 1.1 & $25.8 \pm 0.5 \mathrm{c}$ & 5.5 \\
$6.7+44.4+33.3+22.2$ & 0 & $30.8 \pm 0.7 \mathrm{~b}$ & 4 \\
$6.7+44.4+33.3+22.2$ & 1.1 & $25.6 \pm 0.6 \mathrm{c}$ & 6.5 \\
\hline
\end{tabular}

Notes: a. I = imidacloprid SC, $\mathrm{B}=$ beta-cypermethrin $\mathrm{EC}, \mathrm{T}=$ tebuconazole SC, $\mathrm{D}=$ diethyl aminoethyl hexanoate AS; $\mathrm{b}$. Surface tension values are denoted as "mean \pm SD"; c. The significance analysis of surface tension is divided into three groups according to the concentrations of the adjuvant; $d$. Different lowercase letters mean significant difference in the same group.

Group 2 (SC+EC+EC+AS). Without the adjuvant, the surface tension and spreading coefficient of Group 2 solution with different concentrations are $31.5 \mathrm{mN} / \mathrm{m}$ and $3.8-4$, respectively. After the addition of the adjuvant with three concentrations, the surface tension decreases to $26.5 \mathrm{mN} / \mathrm{m}$ and the spreading coefficient slightly increases to $5-7.5 \mathrm{mN} / \mathrm{m}$. Group 2 solution contains two EC formulations. Take into consideration of the effect of the adjuvant on spreading of beta-cypermethrin and myclobutanil, the minimum amount of the adjuvant is $5.0 \%$ when Group 2 solution is sprayed by UAV to control diseases and pests in wheat field.

Group 3 (EC+EC+EC+AS). There are three EC formulations in Group 3 solution. Surface tensions of Group 3 solution with and without the adjuvant are $25.6-27.6 \mathrm{mN} / \mathrm{m}$ and 30.7-31.3 $\mathrm{mN} / \mathrm{m}$, respectively. As shown in Table 11, the spreading coefficient of the Group 3 solution without the adjuvant is 3.2-4.5. The concentrations of the solution have no influence on spreading coefficient. The adjuvant with concentrations of $0.7-2.0 \%$ has slightly effect on spreading coefficient (4.5-5). A great improvement on spreading coefficient happens when the adjuvant concentration is $5.0 \%$. The spreading coefficient is notably increase to 58 while the adjuvant concentration is $10.0 \%$.

Table 10 Surface tension and spreading coefficient of Group 2 solutions with different concentrations with or without aerial spraying OA

\begin{tabular}{cccc}
\hline $\begin{array}{c}\text { Concentrations of Group } 2 \\
\text { solution } / \mathrm{mL} \cdot \mathrm{L}^{-1}(\mathrm{I}+\mathrm{B}+\mathrm{M}+\mathrm{D})\end{array}$ & $\begin{array}{c}\text { Adjuvant } \\
\text { concentration/\% }\end{array}$ & $\begin{array}{c}\text { Surface tension } \\
/ \mathrm{mN} \cdot \mathrm{m}^{-1}\end{array}$ & $\begin{array}{c}\text { Spreading } \\
\text { coefficient }\end{array}$ \\
\hline $2.8+18.7+14.0+9.3$ & 0 & $30.9 \pm 0.3 \mathrm{a}$ & 4 \\
$2.8+18.7+14.0+9.3$ & 0.7 & $26.3 \pm 0.5 \mathrm{~b}$ & 7.5 \\
$3.2+21.3+16.0+10.6$ & 0 & $31.5 \pm 0.7 \mathrm{a}$ & 4 \\
$3.2+21.3+16.0+10.6$ & 0.7 & $26.2 \pm 0.4 \mathrm{~b}$ & 6 \\
$4.0+26.7+20.0+13.3$ & 0 & $31.2 \pm 0.2 \mathrm{a}$ & 4 \\
$4.0+26.7+20.0+13.3$ & 0.7 & $26.1 \pm 0.4 \mathrm{~b}$ & 5.5 \\
$3.5+23.3+17.5+11.7$ & 0 & $31.1 \pm 0.5 \mathrm{a}$ & 4 \\
$3.5+23.3+17.5+11.7$ & 0.8 & $26.5 \pm 0.1 \mathrm{bc}$ & 5.5 \\
$4.0+26.7+20.0+13.3$ & 0 & $31.1 \pm 0.4 \mathrm{a}$ & 4 \\
$4.0+26.7+20.0+13.3$ & 0.8 & $27.1 \pm 0.5 \mathrm{~b}$ & 5 \\
$5.0+33.3+25.0+16.7$ & 0 & $31.4 \pm 0.6 \mathrm{a}$ & 4 \\
$5.0+33.3+25.0+16.7$ & 0.8 & $25.8 \pm 0.5 \mathrm{c}$ & 5 \\
$4.7+31.1+23.3+15.6$ & 0 & $31.8 \pm 0.7 \mathrm{a}$ & 4 \\
$4.7+31.1+23.3+15.6$ & 1.1 & $25.9 \pm 0.5 \mathrm{~b}$ & 6.5 \\
$5.3+35.6+26.7+17.8$ & 0 & $32.1 \pm 0.6 \mathrm{a}$ & 4 \\
$5.3+35.6+26.7+17.8$ & 1.1 & $26.9 \pm 0.7 \mathrm{~b}$ & 6 \\
$6.7+44.4+33.3+22.2$ & 0 & $31.8 \pm 0.5 \mathrm{a}$ & 3.8 \\
$6.7+44.4+33.3+22.2$ & 1.1 & $25.7 \pm 0.5 \mathrm{~b}$ & 6 \\
\hline
\end{tabular}

Notes: a. I = imidacloprid SC, B = beta-cypermethrin EC, M = myclobutanil EC, $\mathrm{D}=$ diethyl aminoethyl hexanoate AS; $\mathrm{b}$. Surface tension values are denoted as "mean \pm SD"; c. The significance analysis of surface tension is divided into three groups according to the concentrations of the adjuvant; d. Different lowercase letters mean significant difference in the same group.

Table 11 Surface tension and spreading coefficient of Group 3 solutions with different concentrations with or without aerial spraying $\mathrm{OA}$

\begin{tabular}{|c|c|c|c|}
\hline $\begin{array}{c}\text { Concentrations of Group } 3 \\
\text { solution } / \mathrm{mL} \cdot \mathrm{L}^{-1}(\mathrm{~A}+\mathrm{B}+\mathrm{M}+\mathrm{D})\end{array}$ & $\begin{array}{c}\text { Adjuvant } \\
\text { concentration/\%o }\end{array}$ & $\begin{array}{l}\text { Surface tension } \\
\qquad / \mathrm{mN} \cdot \mathrm{m}^{-1}\end{array}$ & $\begin{array}{l}\text { Spreading } \\
\text { coefficient }\end{array}$ \\
\hline $18.7+18.7+14.0+9.3$ & 0 & $30.7 \pm 0.4 \mathrm{a}$ & 4.5 \\
\hline $18.7+18.7+14.0+9.3$ & 0.7 & $27.6 \pm 0.5 b$ & 5 \\
\hline $21.3+21.3+16.0+10.6$ & 0 & $30.7 \pm 0.3 \mathrm{a}$ & 4 \\
\hline $21.3+21.3+16.0+10.6$ & 0.7 & $27.1 \pm 0.3 b$ & 5 \\
\hline $26.7+26.7+20.0+13.3$ & 0 & $30.9 \pm 0.5 \mathrm{a}$ & 3.8 \\
\hline $26.7+26.7+20.0+13.3$ & 0.7 & $27.5 \pm 0.7 b$ & 4.5 \\
\hline $23.3+23.3+17.5+11.7$ & 0 & $31.3 \pm 0.6 \mathrm{a}$ & 3.8 \\
\hline $23.3+23.3+17.5+11.7$ & 0.8 & $26.7 \pm 0.5 b$ & 4.5 \\
\hline $26.7+26.7+20.0+13.3$ & 0 & $31.0 \pm 0.5 \mathrm{a}$ & 3.5 \\
\hline $26.7+26.7+20.0+13.3$ & 0.8 & $26.5 \pm 0.4 b$ & 4.5 \\
\hline $33.3+33.3+25.0+16.7$ & 0 & $31.1 \pm 0.6 \mathrm{a}$ & 3.2 \\
\hline $33.3+33.3+25.0+16.7$ & 0.8 & $26.8 \pm 0.4 \mathrm{~b}$ & 5 \\
\hline $31.1+31.1+23.3+15.6$ & 0 & $31.3 \pm 0.7 \mathrm{a}$ & 3.2 \\
\hline $31.1+31.1+23.3+15.6$ & 1.1 & $25.9 \pm 0.3 b$ & 5 \\
\hline $35.6+35.6+26.7+17.8$ & 0 & $31.2 \pm 0.4 \mathrm{a}$ & 3.2 \\
\hline $35.6+35.6+26.7+17.8$ & 1.1 & $26.7 \pm 0.5 b$ & 4.5 \\
\hline $44.4+44.4+33.3+22.2$ & 0 & $30.8 \pm 0.5 \mathrm{a}$ & 3.2 \\
\hline $44.4+44.4+33.3+22.2$ & 1.1 & $25.6 \pm 0.6 b$ & 4.5 \\
\hline $40.0+40.0+30.0+20.0$ & 0 & $30.9 \pm 0.6 \mathrm{a}$ & 3.5 \\
\hline $40.0+40.0+30.0+20.0$ & 1.0 & $26.3 \pm 0.4 b$ & 5 \\
\hline $40.0+40.0+30.0+20.0$ & 2.0 & $25.9 \pm 0.5 b$ & 5 \\
\hline $40.0+40.0+30.0+20.0$ & 5.0 & $26.1 \pm 0.6 b$ & 15 \\
\hline $40.0+40.0+30.0+20.0$ & 10.0 & $25.8 \pm 0.5 b$ & 58 \\
\hline
\end{tabular}

Notes: a. $\mathrm{A}=$ acetamiprid EC, $\mathrm{B}=$ beta-cypermethrin EC, $\mathrm{M}=$ myclobutanil EC, $\mathrm{D}=$ diethyl aminoethyl hexanoate AS; $\mathrm{b}$. Surface tension values are denoted as "mean \pm SD"; c. The significance analysis of surface tension is divided into four groups according to the concentrations of the adjuvant; d. Different lowercase letters mean significant difference in the same group. 


\section{Discussion}

The performance of aerial spraying tank-mix OA on surface tension and spreading coefficient of three kinds of pesticide formulations used alone and mixed together in high concentration for UAV application to control pests and diseases in wheat field has been studied. In high concentration pesticide solution for UAV application, there is no obvious relationship between the concentration of pesticide solution and the surface tension. Surface tension of pesticide solution can be significantly reduced by the addition of tank-mix OA. When the concentration of the adjuvant is greater than or equal to $\mathrm{CMC}$, the increase of the adjuvant concentration has no obvious effect on the surface tension of the solution. The addition of adjuvant can significantly improve the spreading ability of pesticide solution with high concentration, and the higher the concentration of the adjuvant is, the greater the spreading coefficient is. It indicates that the adjuvant can make pesticide droplets spread on the target better. The results are consistent with the conclusion of the previous research $^{[26]}$

For six single pesticide formulations, the effect of the adjuvant on surface tension and spreading coefficient of pesticide solution is different. The minimum concentration of the adjuvant needed for spraying these pesticides by UAV should be determined according to the characteristics of pesticide formulation and pesticide action mode. For pesticide solution of SC (imidacloprid SC and tebuconazole SC), after the addition of the adjuvant with concentration of $0.5-0.7 \%$, surface tension decreases to $18-22 \mathrm{mN} / \mathrm{m}$, which is significantly less than CST of wheat leaf (36.26$39.00 \mathrm{mN} / \mathrm{m})^{[25]}$. The spreading coefficient $(>17)$ of the solution has been greatly improved by mixing the adjuvant with concentration of $0.5-0.7 \%$. For pesticide solution of AS (diethyl aminoethyl hexanoate AS), the performances of the adjuvant on surface tension and spreading coefficient of the solution are similar to that of tap water. In those solutions, when the adjuvant concentration reaches $\mathrm{CMC}$, surface tension decreases to $20.8 \mathrm{mN} / \mathrm{m}$ and the spreading coefficient is more than 30 . Therefore, it is suggested that OA concentration should be $0.5 \%$ while using UAV to spray pesticide solution of AS alone by low volume and high concentration application. For pesticide solution of EC (beta-cypermethrin EC, acetamiprid EC and myclobutanil EC), the effect of the adjuvant on surface tension of the pesticide solution is similar to the former formulations. However, the performance on spreading coefficient is inferior to that of the former formulations. When the adjuvant concentration is higher than $\mathrm{CMC}(0.7 \%)$, the spreading coefficient of the three solutions is only $5-8$, slightly higher than that of the solutions without the adjuvant. When the concentration of the adjuvant is increased to $2.0 \%$, the spreading coefficients of acetamiprid EC solution and myclobutanil EC solution are 11 and 6, respectively, but that of beta-cypermethrin EC solution is 67 . With the increase of the concentration to $5.0 \%$, the spreading coefficients of acetamiprid EC solution and myclobutanil EC solution increase significantly by 44 and 16, respectively, while the spreading coefficient of beta-cypermethrin EC solution keeps almost the same (68). The reason for that might be caused by the physicochemical properties and the action mode of the solution. Previous research shows that the same adjuvant has different effects on different formulations ${ }^{[27]}$. Beta-cypermethrin EC solution has been obtained the best expansion with the addition of OA under the concentration of 5.0\%, while the other two EC solutions still have gab to the best spread under the same OA concentration. Thus, the adjuvant concentration used for the application of these three pesticides should be determined according to their action mode and spreading characteristics. For UAV application, the OA concentration for beta-cypermethrin EC solution with contact action is $2.0 \%$. The minimum OA concentration for acetamiprid EC solution with stomach toxicity, contact toxicity and internal absorption action should be determined according to the number of pest population. When the number of pest population is below the control threshold, the minimum OA concentration of acetamiprid EC solution is recommended to be $2.0 \%$. When the number of pest population is large, the minimum $\mathrm{OA}$ concentration of acetamiprid EC solution is recommended to be $5.0 \%$. The OA concentration for the application of fungicide myclobutanil EC solution with protective and therapeutic effects is recommended to be $2.0 \%-5.0 \%$.

To facilitate the spreading of droplets on target, the adjuvant concentration for mix-pesticide solution is different from pesticide used alone. From the results, it is found that OA concentration for pesticide mixture solution is higher than that of single pesticide solution to obtain the same spread expansion. Furthermore, OA concentration needed is associated to the number of EC pesticides in solution. For pesticide mixture solution containing one pesticide of $\mathrm{EC}$, the concentration of $\mathrm{OA}$ is recommended to be $2.0 \%$; for pesticide mixture solution containing two or three pesticide of $\mathrm{EC}$, the concentration of $\mathrm{OA}$ is recommended to be $5.0 \%$ - $10.0 \%$. In this study, aerial spraying adjuvant used is aqueous-based adjuvant. In solutions containing EC formulation(s), oil-based adjuvants may have better ability to improve of spreading coefficient of the solution.

\section{Conclusions}

The effects of tank-mix OA on the surface tension and spreading coefficient of six pesticides belonging to three formulations were studied. The results are concluded as the following.

1) OA could significantly lower surface tension and facilitate spreading of pesticide solutions regardless of pesticide concentrations. OA with concentrations higher than $\mathrm{CMC}$ could not decrease surface tension further, but still could significantly improve spreading of the solution.

2) The effect of $\mathrm{OA}$ on surface tension and spreading coefficient on solutions containing pesticide of $\mathrm{EC}$ is inferior to that of SC and AS. For solutions of single pesticide belonging to different formulation, the minimum concentration of $\mathrm{OA}$ is different. The minimum OA concentration for solution of SC and AS ( $0.5 \%-0.7 \%$ ) is lower than that of solutions of EC (2.0\%o-5.0\%o).

3) To facilitate the spreading of pesticide solution, the minimum concentration of OA for mix-pesticide solutions should be higher than CMC. For solutions of several pesticides mixed together, the minimum concentration of OA depends on the number of EC pesticide(s) in the solution. For pesticide solutions with one EC pesticide, the minimum concentration of OA is $2.0 \%$; for pesticide solutions containing two or three EC pesticides, the recommended minimum concentration of OA is $5.0 \%-10.0 \%$.

Considering pesticide field application condition that insecticide, fungicide and plant growth regulator are mixed together for UAV application in wheat field, the minimum of OA concentration used for pesticide used alone or mix together should be evaluated before field application to improve the efficiency of pesticides. 


\section{Funding}

The authors are supported by National Key Research and Development Program of China (2017YFE0122400), Anyang science and technology project (2021C01NY037) and Henan science and technology project (202102110114).

\section{Declaration of Competing Interest}

The authors declare that they have no conflict of interest or personal relationships that could have appeared to influence the work reported in this paper.

\section{[References]}

[1] Zhao X, Cui H, Wang Y, et al. Development strategies and prospects of nano-based smart pesticide formulation. Journal of Agricultural Food Chemistry, 2017. doi: 10.1021/acs.jafc.7b02004.

[2] Zhang $\mathrm{H}, \mathrm{Lu} \mathrm{J}$, Wei D, et al. Wetting state and dynamic spreading behavior of alkyl polyglycoside drop on cucumber leaf surface. Transactions of the Chinese Society of Agricultural Engineering, 2017, 33(3): 81-87. doi: 10.11975/j.issn.1002-6819.2017.03.011. (in Chinese with English abstract)

[3] Adriano A M, Jaime U, Jerson V C G, et al. Impact of tank-mix adjuvants on deposit formation, uticular penetration and rain-induced removal of chlorantraniliprole. Crop Protection, 2015, 78: 253-262. doi 10.1016/j.cropro.2015.09.021

[4] Evandro P P, Carlos G R, Dal P M, et al. Effects of agricultural spray adjuvants in surface tension reduction and spray retention on Eucalyptus leaves. African Journal of Agricultural Research, 2016, 11(40). doi: 10.5897/ajar2016.11349.

[5] Tang X L, Dong J, Li X F, et al. A comparison of spreading behaviors of Silwet L-77 on dry and wet lotus leaves. Journal of Colloid \& Interface Science, 2008, 325(1): 223-227. doi: 10.1016/j.jcis.2008.05.055.

[6] Castro E B, Carbonari C A, Velini E D, et al. Influence of Adjuvants on the Surface Tension, Deposition and Effectiveness of Herbicides on Fleabane Plants. Planta Daninha, 2018, 36. doi: 10.1590/ s0100-83582018360100067.

[7] Janků J, Bartovská L, Soukup J, Jursík M, Hamouzová K. Density and surface tension of aqueous solutions of adjuvants used for tank-mixes with pesticides. Plant Soil Environment, 2012, 58(12): 568-572. doi: 10.1016/j.cropro.2012.05.009

[8] Santos C A M D, Santos R T D S, Della'Vechia J F, et al. Effect of addition of adjuvants on physical and chemical characteristics of $\mathrm{Bt}$ bioinsecticide mixture. Nature-Scientific Reports, 2019. doi: 10.1038/s41598-019-48939-y.

[9] Hazen J L. AdjuvantsTerminology, Classification, and Chemistry. Weed Technology, 2000, 14(4): 773-784. doi: 10.1614/0890-037X(2000) 014[0773:ATCAC]2.0.CO;2.

[10] Stevens P J G. Organosilicone surfactants as adjuvants for agrochemicals. Pestic. Sci, 1993, 38(2-3): 103-122.

[11] Singh M, Mack E R. Effect of organosilicone-based adjuvants on herbicide efficacy. Pestic. Sci, 1993, 38: 219-225. doi: 10.1002/ ps. 2780380217

[12] Huang L X, Hao L F, Yuan J M, et al. Research progress on preparation and application of silicone surfactants for pesticide adjuvants. Silicone Material, 2010, 24(1): 59-64. (in Chinese with English abstract)

[13] Meng Y, Lan Y, Mei G, et al. Effect of aerial spray adjuvant applying on the efficiency of small unmanned aerial vehicle on wheat aphids control. International Journal of Agricultural and Biological Engineering, 2018, 11(5): 46-53. doi: 10.25165/j.ijabe.20181105.4298.

[14] Qin W C, Qiu B J, Xue X Y, et al. Droplet deposition and control effect of insecticides sprayed with an unmanned aerial vehicle against plant hoppers. Crop Protection, 2016, 85: 9-88. doi: 10.1016/ j.cropro.2016.03.018.

[15] He X K, Bonds J, Herbst A, et al. Recent development of unmanned aerial vehicle for plant protection in East Asia. International Journal of Agricultural and Biological Engineering, 2017, 10(3): 18-30. doi: 10.3965/j.ijabe.20171003.3248.

[16] Lan Y, Chen S D, Fritz, B.K. Current status and future trends of precision agricultural aviation technologies. International Journal of Agricultural and Biological Engineering, 2017, 10: 1-17. doi: 10.3965/ j.ijabe.20171003.3088.

[17] He Y, Wu J, Fang H, et al. Research on deposition effect of droplets based on plant protection unmanned aerial vehicle: A review. Journal of Zhejiang University (Agric. \& Life Sci.), 2018, 44(4): 392-398. (in Chinese with English abstract)

[18] Meng Y H, Su J Y, Song J L, et al. Experimental evaluation of UAV spraying for peach trees of different shapes: Effects of operational parameters on droplet distribution. Computers and Electronics in Agriculture, 2020, 170. doi: 10.1016/j.compag.2020.105282.

[19] Wang S L, Song J L, He X K, et al. Performances evaluation of four typical unmanned aerial vehicles used for pesticide application in China. International Journal of Agricultural and Biological Engineering, 2017, 10(4): 22-31. doi: 10.25165/j.ijabe.20171004.3219.

[20] Wang X N, He X K, Song J L, et al. Drift potential of UAV with adjuvants in aerial applications. International Journal of Agricultural and Biological Engineering, 2018, 11(5): 54-58. doi: 10.25165/ ijabe.v11i5.3185.

[21] Hunter J E, Gannon T W, Richardson R J, et al. Coverage and drift potential associated with nozzle and speed selection for herbicide applications using an unmanned aerial sprayer. Weed Technology, 2019, 34(2): 235-240. doi: 10.1017/wet.2019.101.

[22] $\mathrm{He} \mathrm{L}, \mathrm{Hu} \mathrm{T}$, Meng Y H, et al. Influences of spray adjuvants and spray volume on the droplet deposition distribution with unmanned aerial vehicle (UAV) spraying on rice. Plan Protection, 2017, 44(6): 1046-1052. doi: 10.13802/j.cnki.zwbhxb.2017.2016147. (in Chinese with English abstract)

[23] Gu Z Y, Xu X L, Han L J. Study on the Function of Surfactant in the Application of Pesticides. Modern Agrochemicals, 2003, 2(4): 41-42. (in Chinese with English abstract)

[24] Zhang L N, Yang D B, Yuan H Z. Preparation and performance analysis of pesticide droplet wettability test cards. Plant Protection, 2012, 38(2): 103-107. doi: 10.3969/j.issn.0529-1542.2012.02.021. (in Chinese with English abstract)

[25] Gu Z Y, Xu X L, Han L J. Study on the method of measure of the critical surface tension of plants. Modern Agrochemicals, 2002, (2): 18-20. (in Chinese with English abstract)

[26] Wang X N, Liu Y P, Wang S W, et al. Effects on wettability of $10 \%$ difenoconazole water dispersible granule with adjuvants on litchi leaves. Chinese Journal of Pesticide Science, 2018, 20(6): 803-808. (in Chinese with English abstract)

[27] Wang B, Song J L, Zeng A J, et al. Effects of formulations and surfactants on the behavior of pesticide liquid spreading in the plant leaves. Chinese Journal of Pesticide Science, 2012, 14(3): 334-340. (in Chinese with English abstract) 